\title{
"My Little Pony" in adults' eyes. How do men and women watch cartoons? An eye-tracking experiment
}

\author{
Tomasz Gackowski \\ Laboratory of Media Studies, Institute of Journalism \\ University of Warsaw \\ Warsaw, Poland \\ tomasz.gackowski@id.uw.edu.pl
}

\begin{abstract}
This article presents the results of an eye-tracking experiment concerning a part of "My Little Pony" cartoon. The aim of the research was to find out the ways of watching animated auditions for children by adults, and how those ways differ among men and women. The text includes the description of the research procedure and the results of the research in terms of the most important measurements and also with the results of $t$-Student test and ANOVA which were used for directional determining whether the results compared and the relationship between them is uncoincidental. Authors tried to present a new perspective of using the high-tech research tools (enabling behavioral research) and, in further perspective, triangulation of different analysis methods.
\end{abstract}

Keywords-animated auditions; television; eye-tracking tests; content analysis; behavioral research; media studies.

\section{INTRODUCTION}

This article is about to describe an experiment with the use of an eye-tracker, the aim of which was the assessment of the way of watching animated auditions by adults. The text was thought as an attempt to present a new perspective for media studies from the perspective of conducting research projects: using the high-tech research tools (enabling behavioral research) and, in further perspective, triangulation of different analysis methods. In terms of materials it concerns an animated audition dedicated for children, while formally it concerns using behavioral tests (conducted with the use of an eye-tracker) for the assessment of reception of those animated auditions by adults. In further parts of the text, the authors focused on a precise description of an eye-tracking test and its results - also those minor or insignificant for conclusions - in order to present different possibilities of analyzing data collected with the use of the method described. The text ends with summary and discussion which shows different directions for further possible researches in a discussed field. This way the authors discuss a research paradigm which defines a field of possible interdisciplinary empirical research concerning media studies.

At the beginning it is necessary to note that the researches conceptualized in a way proposed by the authors -

\author{
Karolina Brylska \\ Laboratory of Media Studies, Institute of Journalism \\ University of Warsaw \\ Warsaw, Poland \\ karolina.brylska@id.uw.edu.pl
}

assessment of the ways of watching animated auditions ${ }^{\mathrm{a}}$ [1] for children by adults (with the use of an eye-tracking test) are not broadly conducted or at least there are not many publications describing such experiments in main bibliographic catalogues available in Poland. There are incidentally conducted researches concerning animated images (not only cartoons but also instructional or educational animated films) among groups of children and adults with some dysfunctions or disorders, ex. autism, Rett syndrome [2] - [10].

However the authors' intention was slightly different: the whole, broader research is about verifying whether one may observe differences in the way of watching animated auditions by parents of small children and childless adults. The aim of the analyses is the assessment whether and how they differ among those groups: on one hand attention concentration (of an eyesight) on particular frames, on the other, understanding the content of cartoons, their reflections to social world (finding metaphors, hidden meanings, reading punch lines and conclusions) and finally, assessment of attractiveness of these auditions as a specific type of media productions. In order to achieve this goal, a multistage analytical project is conducted, consisting of non-reactive tests (results described in the first article mentioned) and reactive tests: eye-tracking and focus group interviews. This type of methodology triangulation allows broadening the conclusions on every stage of the project and their later collation for holistic description of reception of cartoons in tested groups [1]. ${ }^{\mathrm{b}}$ It may be assumed that the research

\footnotetext{
${ }^{a}$ It is worth mentioning that due to the analyzed material the research is a part of analyses described as scene perception, dedicated to verifying how receivers look at the visual scenes presented on computer screen. The most frequent research questions in this type of experiments concern explaining the factors deciding on directions of looking at frames, and how quickly one may create scene representations in memory [see 11, p. 69]. Testing the dynamic images are generally perceived as difficult - both due to the complexity of the research material (especially sequences of high scenes dynamics) and to the number of raw data gathered for processing. As Andrew Duchowski wrote "the difficulty in analyzing eye movement during watching and interacting with a dynamic stimulus is in synchronizing eyeballs movement in real time and dynamic events that took place during sampling."

b Duchowski emphasized that eye-tracking measures are of quantitative character. Quality data (indicating receivers' satisfaction) may be collected with the use of other methods, ex. in a questionnaire. The advantages of triangulation of research methods and supplementing data aggregated with
} 
described here is of a reconnaissance character, it is used for testing both research material and the tools and methods.

Finally, the introduction should include some remarks concerning eyesight perception in general and crucial in the context of interpreting the results and measures used. A statement of Andrew Duchowski, expressed expressis verbis, seems to be important for understanding the results of eyetracking: "a visual perception of an image (scene) is taking place minutatim (gradually), not in toto (in total). It means that human eyesight is not a fragmentary process of perceptive integration of small areas for building a consistent representation of entirety" $[1, \mathrm{p} .4]$. This view is confirmed by observations of Piotr Francuz, who multiple times wrote that a short gaze ("one glimpse of an eye") is enough for engaging the imagination for reconstructing the whole visual scene and experiencing it as seeing $[18,19]$. The researcher also agrees that: "with the current knowledge of eyesight perception it may be only said that what we subjectively feel as seeing the complete images (scenes or objects) is a creation of observer's mind rather than registration of reality available through the eyes" [12, p.92].

Andrew Duchowski emphasizes selectivity of eyesight attention as a crucial aspect of understanding the results of eye-tracking research. As he states: "Idioms describing a selective character of attention are "what" and "where". The "where" of the eyesight attention corresponds with a visual choice of a specific area of interest from the general field of vision to detailed analysis. It is worth noticing that this choice is frequently made with the use of peripheral vision. The "what" of the eyesight attention corresponds with a detailed analysis of spatial area through a perception channel restricted spatially. Attention dualism of "what" and "where" is important for the eye-tracking researches because the paths of an eyesight show a time progression of fovea centralis of the observer and this way they show momentary visible locations of eyesight attention of the observer" [1, p.13].

\section{THE EYE-TRACKING TEST - A RESEARCH PROCEDURE}

The eye-tracking experiment (as well as the questionnaire and a focus group interview connected with it) was implemented in Laboratory of Media Studies of University of Warsaw. ${ }^{\mathrm{c}}$ The research was conducted with the use of an eye-tracker Tobi X2 - $60 \mathrm{~Hz}$. The participants of the research were male and female students - relatively homogenic groups - of similar or the same age, studying the same field of studies (journalism and social communication) and being at the same or similar year of studies. The group was thought as a control group of the research project - a group of childless adults.

the use of an eye-tracker with data collected with another method were discussed by Holmqvist [11, pp. 95-108, 290-296].

c Detailed information on Laboratory of Media Studies of University of Warsaw infrastructure and the photographs of the rooms are available on www.lbm.uw.edu.pl. As a key advantage of conducting the experiment in a laboratory, Andrew Duchowski mentioned bigger control over the test implementation that finally leads to its coherence and success.
The plot of a twenty-second part of the cartoon episode (the analysis results of which are presented below - "My Little Pony", episode 1, season 1, title: "The Mare in the Moon Captioned") is as follows: the main character, Twilight Sparkle (the purple pony) reluctantly meets noisy and full of energy Pinkie Pie (the pink pony) who, being happy about meeting Twilight, is jumping around her and convincing her of the greatness of a welcoming party that she had organized for the newly-met purple pony in Ponyville. The scene is very dynamic. Twilight Sparkle is calm and even bored of the conversation with the pink pony. Peaceful, subtle, slow moves combined with fast, impulsive movements of Pinkie Pie (that is bouncing, running, jumping around the purple pony) make the whole 20 -second scene (between 24 and 44 second of the whole 4,5-minute part of the cartoon tested) dynamic $\left[1\right.$, p. 178]. ${ }^{\mathrm{d}}$ The stand for the eye-tracking test was organized to minimize distorting factors. The test was conducted in a separate and soundproof room where, during the experiment, there were only a tested person and a tester. An appropriate lighting was chosen (a cold tint of fluorescent light), a chair disabling the possibility of movement of the piece of furniture (without casters), and an appropriate angle of the stand to the window with the daylight beaming. Near the experiment stand there was a chair for the tester put to observe the tested person's behavior and to include possible distorting factors (ex. uneasy movements of the tested person, change of position) in the further results analysis. The tester showed a tested person into the room, pointed to the stand, suggesting sitting down comfortably and explained briefly the course of the experiment. Then the tester filled in the respondent's particulars on the computer (singlehandedly in order to streamline the data collection process) and after that he drew back into the distance of about 2 meters letting the tested person watch a film on the computer screen.

In the following weeks after the experiment the data collected was analyzed and described. This article focuses on the eye-tracking part of the experiment, therefore it includes only the description of the further research procedure of this stage and the data collected at this stage. Moreover, it was decided for the text to present the results of the analysis of the chosen 20 seconds of the cartoon - sequences of the scenes being a content unity and at the same time - because of shortened duration time - enabling an in-depth analysis. While planning the experiment and understanding the research nomenclature, the authors of the research used the main works concerning subject [1] [11] [14] [15] [16].

\section{RESULTS}

In the statistical analysis of eye-tracking results a wide variety of metrics $[1]^{\mathrm{e}}$ offered by TOBII Studio 3.2.1. were

\footnotetext{
d The authors of the research implement the suggestion of A. Duchowski, who advised the KISS formula - Keep It Short and Simple. It helps in managing the data collected. Because of that the eye-tracking experiment material should be reduced more to minutes and seconds rather than hours.

e Duchowski cited Jacob \& Karn [13] the most frequent measurements used with eye-tracking: fixation, fixation (gaze) duration, fixation rate (overall), fixation duration mean (overall), numer of fixations (overall), scanpath (fixation sequence), area of interest (AOI), gaze \% (prop, of time)
} 
used. 20 persons out of the 23 tested with an eye-tracker were finally chosen whose samples achieved during the test were no less than 80 percent (in some cases samples were up to 95 percent). It is worth noting that the highest the percentage, the more precise the measurement. Among 20 persons there were 10 men and 10 women. For statistical operations taken it was assumed that those groups are independent. It was necessary to ascertain at this stage of data processing whether sex - usually being the most diversifying independent variable in social and behavioral researches - impacts the differences in the mean for particular measures and if so, then how? [1, p.162]. At the end a statistical test - t-Student \& Anova - was conducted in order to ascertain if the determined differences based on the compared means for particular measures for every participant of the research (qualified for the group of 20) are not coincidental.

In this perspective the significance level is crucial, which is a maximum possible probability of making a type I error (usually denoted by the symbol $\alpha$ ). This way determines a maximum risk of an error which a researcher would be willing to accept. The choice of $\alpha$ value depending on the researcher, nature of the problem, and how accurately one wants to verify the hypotheses - it is usually assumed that $\alpha$ $=0.05$. The value of the assumed level of significance is compared with the $\mathrm{P}$ value calculated from the statistical test. It is important to remember that if a $\mathrm{P}$ value is higher it means that there is no need to reject the so called zero hypothesis $\mathrm{H} 0$, which usually states that the observed effect is a coincidence.

The first measurement regarded time, measuring the period between presenting the stimulus to the first fixation $[1, \text { p. } 46]^{\mathrm{f}}$ on the researcher's area of interest (AOI) (scheme: stimulus - start - fixation - AOI) (time to first fixation). It means, how much time it took a tested person to look at our area of interest $[11]^{\mathrm{g}}$. In the scene tested there were two main areas of interest distinguished - the two ponies mentioned: Twilight Sparkle (the purple pony) and Pinkie Pie (the pink pony). Figures presented below show the mean for this measurement - both for men and women (sex - independent variable) - in case of both areas of interest (AOI - metrics dependent variable). Another measurement is the number of fixations before fixating (looking at) of the tested person on a particular AOI for the first time (fixations before). Next, duration of the first fixation on the AOI chosen (first fixation duration) which is how long was the first fixation on the chosen area of interest in the scene analyzed. Another pages present other different measures which confirm an

per AOI, numer of fixations per AOI, gaze duration mean per AOI,. Holmqvist [11, pp. 301-453] mentioned 120 eye-tracking measures.

$\mathrm{f}$ Following Duchowski, fixation is defined as ,eye movement that stabilizes retina on still object of interest." The author also emphasized that during fixation there are micromovements of an eyeball (microtrembling, microdrifts, microsaccades)

g ${ }^{11}$ AOI (areas of interest) may be defined by such parts of a frame which concentrated eye fixation of the subjects (according to both duration and their number). They were concentrated mainly around the characters appearing on the screen and dominant elements of scenography. About the essence of AOI, their types and interpretation see [11, pp. 187-230]. observation that may be mentioned now. Even though men fixated later on the characters of a given scene, they did it averagely longer but more rarely.

Another measure is an average time of all fixations on a chosen AOI (fixation duration) determining the length of average fixations on a given area of interest. It turns out that women more often fixate on the characters of the scene of the cartoon - in case of Pinkie Pie - this finding is of uncoincidental character (see the statistics included below). Those findings are worth comparing with other data presented below. Next measurement is a total time of all the fixations on a given AOI during the whole experiment (total fixation duration). In other words, it shows the length of all the fixations on a given image in a tested time of exposition on specific stimulus (in this case during the 20 seconds of the whole scene from "My Little Pony"). Finally, the number of fixations on a given AOI (fixation count) - how many times the tested person fixated (looked at) on the same area of interest during the measurement. In case of the time measuring duration of every single fixation on a given AOI (visit duration) a time of a particular visit was measured. The interval measurement is taken for a visit - from the beginning of the first fixation to another being outside a given AOI. Total duration time of all fixations on a given AOI is also connected to the previous measure (total visit duration [observation length]). It is a total time - length - of observing a given AOI in particular time - in this case a scene of "My Little Pony". A measurement that is worth mentioning is also the number of visits - fixations - of a tested person on a given AOI (visit count [observation count]).

Due to lack of space the mesures are not precisely presented in figures in this version of paper (the figures comparing mean values of every variable divided into the sex of the subjects [values for women and values for men] with the use of t-Student test are prepared and ready to be published in the extended version of article).

It is worth noting that the presented results should be looked at all together, in a panoramic manner. The differences determined, confirmed with a statistical test (the difference is uncoincidental) tell a researcher nothing if they are looked at individually. It is triangulation of the two approaches to the eye-tracking results - a statistical approach and visual approach (cluster $\left.{ }^{\mathrm{h}}\right)$ [12] consisting in analyzing visualized by the software, aggregated test results - that gives interesting and complete results [1].

Also it is worth conducting a bivariate analysis determining the relationship between the dependent variable and the sex of subjects and the cartoon character. In a test constructed in such a way, a variance of the whole data sample consists of four elements: variance resulting from one

h Clusters are created as a result of fixations grouping - the biggest concentration of stoppage of the eyes movement makes a cluster which is the most attention catching area of a frame. Clusters may be later easily transformed into areas of interest (AOI) or confronted with AOI if they have been assumed before generating clusters. Clusters present the results for particular groups of subjects tested (selected according to various criteria). 
variable (the sex - Table 1: gota $\$$ sex), variance resulting from second variable - the observed cartoon characters Twilight Sparkle and Pinkie Pie (Table 1: gota\$varviz), variance from interactions between those variables (Table 1: gota\$sex:gota\$varviz), and finally residual/unexplained variance (Table 1: Residuals - key: DF - degrees of freedom; SQ - sum of squares; Mean sq - mean sum of squares; F.value - F-test value; $P R(>F)$ - significance of Ftest and statistical significance). The table below presents the results of all the data executed within bivariate ANOVA test (with the use of statistical package R) dedicated for all the eye-tracking measurements used (the same as in case of tStudent test) including division into sex and cartoon characters of the scene analyzed. The analysis of the table presented below clearly shows variables where significant and uncoincidental differences take place. Only in the case of Fixation duration there is a significant difference in case of the sex, the cartoon character analyzed as well as the relation between those two variables. The test gave the significant result of 0.001 . When it comes to Fixations Before the difference is significant both for the sex and the cartoon character analyzed. Therefore, there is no coincidence in differentiating due to the sex and according to the character (Twilight Sparkle and Pinkie Pie).

TABLE I. ANOVA TEST - SEX VS AOI MEASUREMENT. SOURCE: OWN RESEARCH

\begin{tabular}{|c|c|c|c|c|c|c|}
\hline Measurement $^{\mathbf{a}}$ & Df & Sum sq & Mean sq & F value & $\operatorname{Pr}(>\mathbf{F})$ & Sign. \\
\hline Time to first fixation & Df & Sum sq & Mean sq & F value & $\operatorname{Pr}(>\mathbf{F})$ & Sign. \\
\hline Sex & 1 & 12,2 & 12,199 & 4,032 & 0,0522 & . \\
\hline Heroes (Twilight Sparkle \& Pinkie Pie) & 1 & 2,28 & 2,28 & 0,754 & 0,3911 & \\
\hline Sex vs. Heroes & 1 & 0,54 & 0,536 & 0,177 & 0,6764 & \\
\hline Residuals & 36 & 108,93 & 3,026 & & & \\
\hline Fixations Before & Df & Sum sq & Mean sq & F value & $\operatorname{Pr}(>\mathbf{F})$ & \\
\hline Sex & 1 & 34,22 & 34,22 & 5,649 & 0,0229 & $*$ \\
\hline Heroes (Twilight Sparkle \& Pinkie Pie) & 1 & 65,03 & 65,03 & 10,733 & 0,00233 & $* *$ \\
\hline Sex vs. Heroes & 1 & 0,02 & 0,02 & 0,004 & 0,94914 & \\
\hline Residuals & 36 & 218,1 & 6,06 & & & \\
\hline First Fixation Duration & Df & Sum sq & Mean sq & F value & $\operatorname{Pr}(>\mathbf{F})$ & \\
\hline Sex & 1 & 0,0308 & 0,0308 & 1,186 & 0,2835 & \\
\hline Heroes (Twilight Sparkle \& Pinkie Pie) & 1 & 0,0087 & 0,0087 & 0,335 & 0,5664 & \\
\hline Sex vs. Heroes & 1 & 0,1452 & 0,1452 & 5,589 & 0,0236 & $*$ \\
\hline Residuals & 36 & 0,9353 & 0,02598 & & & \\
\hline Fixation Duration & Df & Sum sq & Mean sq & F value & $\operatorname{Pr}(>\mathbf{F})$ & \\
\hline Sex & 1 & 241,5 & 241,5 & 71,12 & $4,78 \mathrm{E}-10$ & $* * *$ \\
\hline Heroes (Twilight Sparkle \& Pinkie Pie) & 1 & 239,5 & 239,5 & 70,51 & $5,31 \mathrm{E}-10$ & $* * *$ \\
\hline Sex vs. Heroes & 1 & 236,5 & 236,5 & 69,65 & $6,15 \mathrm{E}-10$ & $* * *$ \\
\hline Residuals & 36 & 122,3 & 3,4 & & & \\
\hline Total Fixation Duration & Df & Sum sq & Mean sq & F value & $\operatorname{Pr}(>\mathbf{F})$ & \\
\hline Sex & 1 & 54,9 & 54,94 & 4,349 & 0,0442 & * \\
\hline Heroes (Twilight Sparkle \& Pinkie Pie) & 1 & 7,4 & 7,43 & 0,588 & 0,4481 & \\
\hline Sex vs. Heroes & 1 & 10,6 & 10,59 & 0,838 & 0,366 & \\
\hline Residuals & 36 & 454,8 & 12,63 & & & \\
\hline Fixation Count & Df & Sum sq & Mean sq & F value & $\operatorname{Pr}(>\mathbf{F})$ & \\
\hline Sex & 1 & 416 & 416 & 3,419 & 0,0727 & . \\
\hline Heroes (Twilight Sparkle \& Pinkie Pie) & 1 & 6 & 5,6 & 0,046 & 0,831 & \\
\hline Sex vs. Heroes & 1 & 81 & 81,2 & 0,668 & 0,4193 & \\
\hline Residuals & 36 & 4380 & 121,7 & & & \\
\hline Visit Duration & Df & Sum sq & Mean sq & F value & $\operatorname{Pr}(>\mathbf{F})$ & \\
\hline Sex & 1 & 0,0837 & 0,08372 & 4,014 & 0,05269 & . \\
\hline Heroes (Twilight Sparkle \& Pinkie Pie) & 1 & 0,2146 & 0,21462 & 10,291 & 0,00281 & $* *$ \\
\hline Sex vs. Heroes & 1 & 0,0189 & 0,01892 & 0,907 & 0,34718 & \\
\hline Residuals & 36 & 0,7508 & 0,02086 & & & \\
\hline Total Visit Duration & Df & Sum sq & Mean sq & F value & $\operatorname{Pr}(>\mathbf{F})$ & \\
\hline Sex & 1 & 14,4 & 14,41 & 1,334 & 0,256 & \\
\hline Heroes (Twilight Sparkle \& Pinkie Pie) & 1 & 26,8 & 26,81 & 2,482 & 0,124 & \\
\hline Sex vs. Heroes & 1 & 17,5 & 17,49 & 1,619 & 0,211 & \\
\hline Residuals & 36 & 388,9 & 10,8 & & & \\
\hline Visit Count & Df & Sum sq & Mean sq & F value & $\operatorname{Pr}(>\mathbf{F})$ & \\
\hline Sex & 1 & 313,6 & 313,6 & 8,237 & 0,00683 & $* *$ \\
\hline Heroes (Twilight Sparkle \& Pinkie Pie) & 1 & 84,1 & 84,1 & 2,209 & 0,14592 & \\
\hline Sex vs. Heroes & 1 & 36,1 & 36,1 & 0,948 & 0,33668 & \\
\hline Residuals & 36 & 1370,6 & 38,07 & & & \\
\hline
\end{tabular}


In other eye-tracking variables, single, statistically significant differences were noted. In case of the sex differentiation it was 0.05 of Total Fixation Duration and 0.01 of Visit Count. When it comes to the differences between the characters - Pinkie Pie and Twilight Sparkle the significant differences were noted in case of Visit Duration -0.01 .

Concluding this collation, it should be noted that it would be worth it - for the solidity of measurements and their significance - to conduct similar experiments on larger group of participants in order to define more unequivocally the uncoincidental differences in terms of watching the chosen scenes in cartoons by women and men. Based on certain directional observations one may make observations as follows, concerning the conducted experiment on the chosen video sequence from "My Little Pony", taking into consideration the metrics used.

The general conclusions from the statistical analyses of the eye-tracking test of "My Little Pony" fragment may lead to some interesting observations regarding the way of watching the main characters by men and women. According to the data obtained in the study men fixated (looked at) on the characters of the analyzed scene - Pinkie Pie and Twilight Sparkle - later. In the case of the purple pony this difference is not coincidental according to statistically significant result of t-Student test. It can be assumed that with greater number of samples and/or more people tested with an eye-tracker a statistically significant result could be visible also in the case of the pink pony. This observation is confirmed by another, regarding the number of fixations done by the tested person before the eye fixated on the particular characters - the ponies talking to each other. According to joint data - in the case of Pinkie Pie the average fixation count was more than six times bigger with men than with women (the result - according to t-Student test - turned out to be statistically insignificant $-\mathrm{p}$ value $=$ 0.0860). When it comes to the purple pony the distance was definitely smaller. Those observations, creating a consistent image of differences in the way of watching characters of the analyzed scene from "My Little Pony" are confirmed by another measurement regarding total duration time of fixations on particular ponies. An average mean difference in total fixation time in case of men and women - when it comes to Pinkie Pie - is $4.12 \mathrm{~ms}$ while in case of Twilight Sparkle it was 1.49. The results obtained while analyzing AOI of the pink pony turned out to be - within the t-Student test - statistically very significant $-\mathrm{p}=0.0072$ (which is even $\alpha=0.01)$. In the context of this result, interesting conclusions were noted in case of measuring the fixations number - especially in the case of Pinkie Pie. According to the figures the mean number of fixations for women was higher of exactly 9.96 while the difference identified, according to the t-Student test result turned out to be uncoincidental and statistically significant $-\mathrm{p}=0.0343$.

When it comes to the results in case of Twilight Sparkle, the mean number of fixations for women was also higher than for men (higher of exactly 5.23). However, in case of purple pony, data turned out to be statistically insignificant (t-Student).

Interesting findings are brought by the length of a gaze (visit duration) even though in cases of both ponies the results were not statistically significant (with Twilight Sparkle as the AOI it was the closest result -0.0750 in tStudent test). It turns out that - concerning the findings above - even though men fixated on the cartoon characters later and more rarely but when they did fixate (looked at) on Pinkie Pie and/or Twilight Sparkle, they looked at them longer than women. The time of such a visit was longer - for Pinkie Pie of $0.04 \mathrm{~ms}$, for Twilight Sparkle of $0.11 \mathrm{~ms}$. It is also worth analyzing in the same context the measure of total duration time of looking at Pinkie Pie and Twilight Sparkle. When it comes to the total fixation duration on the discussed AOI - areas of interest - the results are more favorable for women - whose visits (gazes) were shorter but more frequent and achieved faster.

TABLE II. DifFERENCES BETWEEN MEN AND WOMEN IN WATCHING ANALYZED SCENE OF “My LitTLE PONY”

\begin{tabular}{|c|c|c|}
\hline $\begin{array}{l}\text { Metrics type } \\
\text { (average) }\end{array}$ & Men & Women \\
\hline $\begin{array}{l}\text { Time to first } \\
\text { fixation }\end{array}$ & $\begin{array}{l}\text { Averagely later fixate on the main characters of the video sequence } \\
\text { chosen }\end{array}$ & $\begin{array}{l}\text { Averagely fast fixate on the main characters of the video sequence } \\
\text { chosen }\end{array}$ \\
\hline $\begin{array}{l}\text { First fixation } \\
\text { duration }\end{array}$ & $\begin{array}{l}\text { Averagely longer was the first fixation on Pinkie Pie, shorter on } \\
\text { Twilight Sparkle }\end{array}$ & $\begin{array}{l}\text { Averagely shorter was the first fixation on Pinkie Pie, longer on } \\
\text { Twilight Sparkle }\end{array}$ \\
\hline $\begin{array}{l}\text { Fixation } \\
\text { duration }\end{array}$ & $\begin{array}{l}\text { Average fixation duration on Pinkie Pie was shorter, in case of } \\
\text { Twilight Sparkle it was the same }\end{array}$ & $\begin{array}{l}\text { Average fixation duration on Pinkie Pie was longer, in case of Twilight } \\
\text { Sparkle it was the same }\end{array}$ \\
\hline $\begin{array}{l}\text { Fixations } \\
\text { before }\end{array}$ & $\begin{array}{l}\text { Averagely considerably more fixations were done by men before } \\
\text { their eyesight went on Pinkie Pie, in case of Twilight Sparkle this } \\
\text { dominance was to a lesser extent }\end{array}$ & $\begin{array}{l}\text { Averagely considerably less fixations were done by women before their } \\
\text { eyesight went on Pinkie Pie, in case of Twilight Sparkle this difference } \\
\text { was to a lesser extent }\end{array}$ \\
\hline $\begin{array}{l}\text { Total fixation } \\
\text { duration }\end{array}$ & $\begin{array}{l}\text { Total average fixation duration was averagely shorter both in case } \\
\text { of Pinkie Pie and Twilight Sparkle }\end{array}$ & $\begin{array}{l}\text { Total average fixation duration was averagely longer both in case of } \\
\text { Pinkie Pie and Twilight Sparkle }\end{array}$ \\
\hline $\begin{array}{l}\text { Fixation } \\
\text { count }\end{array}$ & $\begin{array}{l}\text { Average fixation count on Pinkie Pie and Twilight Sparkle was } \\
\text { lower }\end{array}$ & Average fixation count on Pinkie Pie and Twilight Sparkle was higher \\
\hline Visit duration & $\begin{array}{l}\text { Average visit duration on Pinkie Pie and Twilight Sparkle was } \\
\text { longer }\end{array}$ & Average visit duration on Pinkie Pie and Twilight Sparkle was shorter \\
\hline $\begin{array}{l}\text { Total visit } \\
\text { duration }\end{array}$ & $\begin{array}{l}\text { Average Total visit duration on Pinkie Pie and Twilight Sparkle } \\
\text { was shorter (insignificantly in case of purple pony) }\end{array}$ & $\begin{array}{l}\text { Average Total visit duration on Pinkie Pie and Twilight Sparkle was } \\
\text { longer (insignificantly in case of purple pony) }\end{array}$ \\
\hline Visits count & $\begin{array}{l}\text { Average visits count on AOI - Pinkie Pie and Twilight Sparkle - } \\
\text { was considerably lower }\end{array}$ & $\begin{array}{l}\text { Average visits count on AOI - Pinkie Pie and Twilight Sparkle - was } \\
\text { considerably higher }\end{array}$ \\
\hline
\end{tabular}

Figure no. 1. Visual differences between men and women in analyzed scene of "My Little Pony" (all/men/women) 

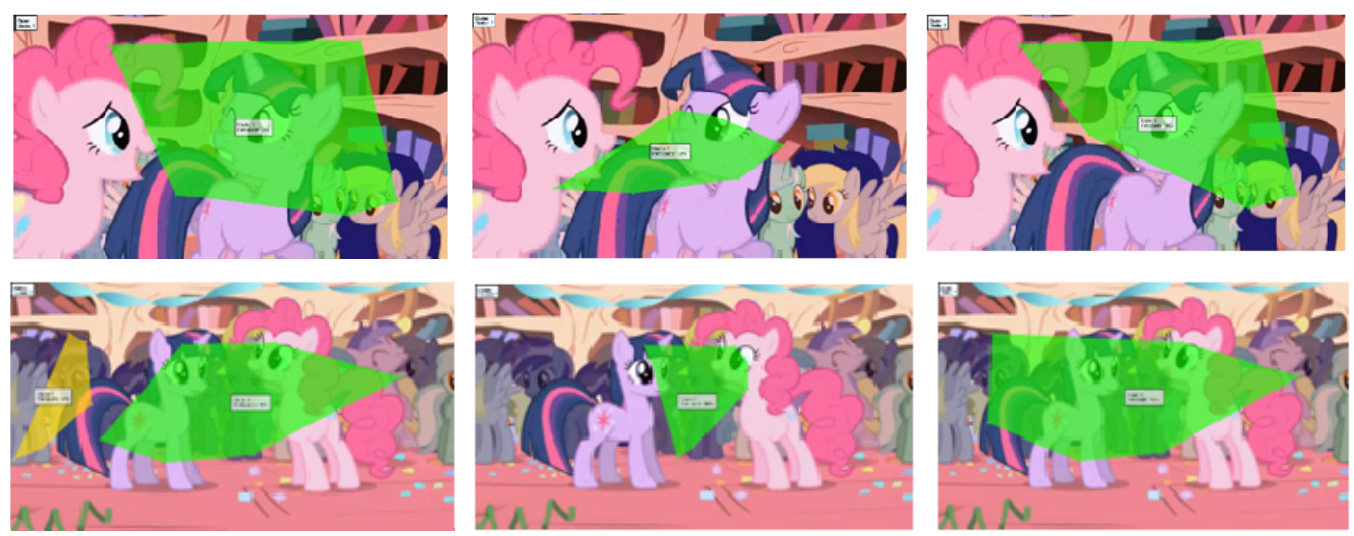

Figure no. 1. Visual differences between men and women in analyzed scene of "My Little Pony" (all/men/women)

In case of the pink pony the total visit duration was longer of exactly $2.52 \mathrm{sec}$, while for the purple pony it was $0.26 \mathrm{sec}$. T-Student test in case of Pinkie Pie showed that the observed difference is statistically important $-\mathrm{p}=0.0282$.

At the end, the total visits count was shown. Such visits took place more frequently in case of women, concerning Pinkie Pie of about 7.69, and Twilight Sparkle of about 4.05. The difference observed in case of the pink pony turned out to be strongly statistically significant, with $p=0.0151$. The measurement of number of visits shows clearly - which cannot be surprising in the light of previously discussed results - that women looked more often at the characters of the analyzed scene from "My Little Pony". Those arrangements enable reaching to some conclusions regarding how a specific, dynamic scene of a cult cartoon "My Little Pony" with a lively interaction with two ponies is watched by men and women. It is also visible on the pictures - frames - above, caught by Tobii Studio with clusters applied cumulated, delineated ranges - areas of identified fixations of a tested group, also divided between men and women. It turns out that the results from statistical analysis coincide with observations from the analysis of visual results - eyetracking clusters. Those exemplary frames are worth comparing. They are presented as follows: all subjects tested, men, and women.

It is clearly visible that all the participants focused their eyesight on the central part of the frame [1, pp. 222-225]. It is not surprising. However, in case of men it is even more visible. Men, in a specific manner, focused on interaction between ponies, on what was happening between them - the space between them (strongly centralized in the frame) - less on the ponies themselves as characters of the scene $[1, p$. 139]. What also sticks out when one takes into consideration the size, distribution and outline of the presented clusters is the fact that women watched a given scene more broadly, spaciously, encompassing the context of interaction, they also paid more attention to the ponies and their appearance as a whole.

\section{SUMMARY AND DISCUSSION}

Observations described above should be also deepened by the analysis of viewing of other scenes from the given animated TV series. Another stages of data processing will be dedicated to it. It is possible that this way of watching cartoons by adults (childless) is characteristic - differentiated by the sex. Also on the statistical level there are presumptions to claim that some observations comprising for the clear image of the way of watching the scene by men and women give some assumptions for generalizing the conclusions - at least in the context of this cartoon, which is cult and well-known worldwide.

It is worth adding that a great task for the researches is not only determining particular differences in the ways of watching, make them probable with the statistical tests but also make an attempt to explain the whole process of watching - why is it that way and not another. Bearing such task in mind, the authors of the project assumed triangulation of the research methods which would enable, at least partially, to explain to some extent the reasons for a particular way of watching a cartoon by the subjects. The post-eye-tracking questionnaires and focus group interviews are used for this explanation. The research team assumes that the answers declared by the tested persons have a hidden explanation of the differences observed at the stage of eyetracking tests, while the attempt of method triangulation planned itself allows some kind of socializing of the results of behavioral tests. Data collected in the questionnaires and during focuses are processed and are about to be presented in separate texts (lack of space). After a preliminary assessment of subjects' answers it can be stated that they provide very interesting results - above all, they prove that the cartoon construction itself generates a great metaphorization potential and a character and plot polysemy provides the receivers a starting point for broad interpretation, coming from various areas of social life. It means that the audition may be attractive not only for children, students (and probably also parents) may find there the mechanisms stricte fit for relationships and actions of adults. For example some answers which were repeated by the responders during the focus group interviews may be cited that the cartoon may be interpreted as a metaphor of corporation and its characters as role models of femininity and masculinity, and the language used in audition as intertextual, full of cultural references and because of that partially understandable for adults only. It should be reminded that the results presented here refer to the group of students, which is treated in the project as a zero group, verifying for the proper group - parents. A key assumption of the research project was that next to the sex, the most important independent variable explaining the 
differences between the way of watching cartoons is the fact of having children - having a status of being a parent.

While evaluating the eye-tracking test, some areas for modification and broadening for achieving more complex and more interesting results may be indicated. Surely it would be interesting to use different, contrasting in context cartoon for the analysis such as "Total Drama Action" broadcasted by Cartoon Network - it would be a great research challenge to verify whether, with different cartoon aesthetics (colors, line), with different plot and frames dynamics, and completely different language layer, the way of perceiving the image by men and women changes. Another interesting topic would be contrasting animated and fiction auditions for children in the context of their reception by adults. Does the form of production change anything in the reception and understanding, which should be(and usually are) based on similar, universal schemes, refer to the specific values and present typical characters? Finally, the unknown factor - although difficult to say how significant remains the age of the tested persons. Would older receivers, for example 50-year-olds, watch the cartoon in a different way than younger, 20-year-olds? If it would be impossible to see significant differences in the eye-tracking test, would there be, and how would those differences look like at the interpretation stage? To what extent would they be rooted in cultural universals, and to what extent would they be conditioned with personal experiences of the responders?

The perspectives presented above give a glimpse of only a part of possibilities which are given by eye-tracking together with other methods of analyzing media messages. Thanks to such conceptualization a traditional research for media experts can be supplemented with complex reception analysis both on behavioral and interpretative level. It seems that such holistic attitude meets the experimental demands of the new field - interdisciplinary media studies. And this particular attitude should and will be developed.

\section{REFERENCES}

[1] A. Duchowski, The eyetracking methodology. Theory and Practice, London: Springer-Verlag, 2007.

[2] D. Riby, P. J. B. Hancock, "Looking at movies and cartoons: eyetracking evidence from Williams syndrome and autism", Journal of Intellectual Disability Research, vol. 53(2), pp. 169-181, February 2009.

[3] A. Helo, S. Pannasch, L. Sirri, P. Rama, "The maturation of eye movement behavior: Scene viewing characteristics in children and adults", Vision Research, vol. 103, pp. 83-91, October 2014.

[4] J. N. van der Geest, C. Kemner, G. Camfferman, M.N. Verbaten, H. van Engeland, "Looking at images with human figures: comparison between autistic and normal children", Journal of Autism and Developmental Disorders, vol. 32(2), pp. 69-75, April 2002.

[5] A. Klin, W. Jones, R. Schultz, F. Volkmar, D. Cohen, "Visual fixation patterns during viewing of naturalistic social situations as predictors of social competence in individuals with autism", Archives of General Psychiatry, vol. 59(9), pp. 809-816, September 2002.

[6] M. Swanson, M. Siller, "Brief Report: Broad Autism Phenotype in Adults is Associated with Performance on an Eye-Tracking Measure of Joint Attention", Journal of Autism \& Developmental Disorders, vol. 44(3), pp. 694-702, March 2014.
[7] A. Djukic, M. McDermott Valicenti, K. Mavrommatis, CL Martins, "Rett Syndrome: Basic Features of Visual Processing-A Pilot Study of Eye-Tracking", Pediatric Neurology, vol. 47(1), pp. 25-29, July 2012.

[8] C. Cambra, O. Penacchiob, N. Silvestrec, A. Lealc, "Visual attention to subtitles when viewing a cartoon by deaf and hearing children: an eye-tracking pilot study", Perspectives: Studies in Translatology, vol. 22(4), pp. 607-617, December 2014.

[9] T. A. Horsley, B. O. de Castro, M. van der Schoot, "In the Eye of the Beholder: Eye-Tracking Assessment of Social Information Processing in Aggressive Behavior", Journal of Abnormal Child Psychology, vol. 38 (5), pp. 587-599, July 2010.

[10] Q. Guillon, N. Hadjikhani, S. Baduel, B. Rogé, "Visual social attention in autism spectrum disorder: Insights from eye tracking studies", Neuroscience and Biobehavioral Reviews, vol. 42, pp. 279297, May 2014.

[11] K. Holmqvist, M. Nyström, R. Andersson, R. Dewhurst, H. Jarodzka, J. van de Weijer, Eye Tracking A Comprehensive Guide to Methods and Measures. Oxford: Oxford University Press, 2011.

[12] P. Francuz, Imagia. W kierunku neurokognitywnej teorii obrazu [Towards a neurocognitive theory of image], Lublin: Wydawnictwo Katolickiego Uniwersytetu Lubelskiego, 2013.

[13] R. J. K. Jacob, K. S. Karn, Eye tracking in Human-Computer Interaction and usability research: Ready to deliver the promises. In The mind's eye: Cognitive and applied aspects of eye movement research, J. Hyönä, R. Radach, \& H. Deubel, Eds., Amsterdam, 2003, pp. 573-605.

[14] M. Land, B. Tatler, Looking and Acting. Vision and eye movements in natural behaviour, Oxford: Oxford University Press, 2009.

[15] R. van Gompel, M. H. Fischer, W. S. Murray, R. L. Hill, Eds., Eye Movements. A window on Mind and Brain. Amsterdam: Elsevier Science, 2007.

[16] R. Hammoud, Eds., Passive Eye Monitoring. Algorithms, Applications and Experiments, Berlin Heidelberg: Springer-Verlag 2008.

[17] K. Rayner, "Eye Movements in Reading and Information Processing: 20 Years of Research, Psychological Bulletin”, vol. 124, pp. 372-422, November 1998.

[18] P. Francuz, Eds., Na ścieżkach neuronauki [On the Neuroscience paths], Lublin: Wydawnictwo Katolickiego Uniwersytetu Lubelskiego, 2010.

[19] P. Francuz, Eds., Obrazy w umyśle. Studia nad percepcja i wyobraźnią [Pictures in the Mind. Studies in Perception and Imagery], Warszawa: Wydawnictwo Naukowe SCHOLAR, 2007. 